\title{
Spreads enriched with plant sterols, either esterified 4,4-dimethylsterols or free 4-desmethylsterols, and plasma total- and LDL-cholesterol concentrations
}

\author{
Aafje Sierksma, Jan A. Weststrate* and Gert W. Meijer \\ Unilever Nutrition Centre, Unilever Research Vlaardingen, Olivier van Noortlaan 120, 3133 AT Vlaardingen, \\ The Netherlands
}

(Received 11 June 1998 - Revised 19 April 1999 - Accepted 5 May 1999)

\begin{abstract}
In a 9-week study seventy-six healthy adult volunteers with an average age of 44 (SD 11) years, with baseline plasma total cholesterol levels below $8 \mathrm{mmol} / \mathrm{l}$, received in a balanced, doubleblind, crossover design, a total of three different table spreads for personal use. Two spreads were fortified either with free (non-esterified) vegetable-oil sterols, mainly from soyabean oil (31 $\mathrm{g}$ sterol equivalents $/ \mathrm{kg} ; 0.8 \mathrm{~g} / \mathrm{d}$ ) or sheanut-oil sterols $(133 \mathrm{~g}$ sterol equivalents $/ \mathrm{kg} ; 3.3 \mathrm{~g} / \mathrm{d})$. One spread was not fortified (control). Average intake of spread was $25 \mathrm{~g} / \mathrm{d}$ for 3 weeks. None of the spreads induced changes in blood clinical chemistry or haematology. Plasma total- and LDL-cholesterol concentrations were statistically significantly reduced by $3.8 \%$ and $6 \%$ (both $0.19 \mathrm{mmol} / \mathrm{l}$ ) respectively, for the spread enriched with free soyabean-oil sterols compared with the control spread. The spread enriched with sheanut-oil sterols did not lower plasma totaland LDL-cholesterol levels. None of the plant-sterol-enriched spreads affected plasma HDL-cholesterol concentrations. Plasma-lipid-standardized concentrations of $\alpha$-plus $\beta$-carotene were not statistically significantly affected by the soyabean-oil sterol spread in contrast to lipidstandardized plasma lycopene levels which showed a statistically significant decrease (9.5\%). These findings indicate that a daily intake of free soyabean-oil sterols as low as $0.8 \mathrm{~g}$ added to a spread is effective in lowering blood total- and LDL-cholesterol levels with limited effects on blood carotenoid levels. The lowering in total- and LDL-cholesterol blood levels due to consumption of the vegetable-oil-sterol-enriched spread may be helpful in reducing the risk of CHD for the population.
\end{abstract}

Plant sterols: Lipids: Carotenoids

The major manifestation of cardiovascular disease is CHD, which remains the leading cause of death in the developed world. Atherosclerosis, which damages the coronary arteries, is the primary disease mechanism of CHD (Reitsma, 1995). Hypercholesterolaemia contributes to the atherosclerosis and its clinical manifestations such as coronary artery occlusion and ischaemic myocardial infarction (Steinberg \& Witztum, 1990).

Lowering blood total- and LDL-cholesterol levels has been advocated as a method to decrease the incidence of CHD (Probstfield \& Rifkind, 1991; Cucherat \& Boissel, 1993). The benefits of serum cholesterol concentration reduction are related to age; a $10 \%$ reduction in total serum cholesterol concentration produces a reduction in IHD of $50 \%$ at age $40,40 \%$ at age $50,30 \%$ at age 60 , and $20 \%$ at age 70 . The benefit can be realised quickly, the greater part after 2 years and the full benefit after 5 years (Law et al. 1994). Reduction in the blood cholesterol concentration not only slows the process of atherosclerosis, but can also result in regression of atherosclerosis (Levine et al. 1995).

Dietary modification is the first step in lowering blood cholesterol levels, for example, replacing saturated fatty acids by unsaturated fatty acids (Mensink \& Katan, 1992) and increasing the intake of soluble fibres (Ripsin et al. 1992). In addition to unsaturated fatty acids and soluble fibres, plant sterols, such as sitosterol, may also reduce blood cholesterol levels (Pollak \& Kritchevsky, 1981). Sitosterol at intakes of 3-20 g/d reduces blood cholesterol levels by $5-15 \%$ in human studies without major sideeffects (Farquhar \& Sokolow, 1958; Oster et al. 1976; Lees et al. 1977; Schwartzkopff \& Jantke, 1978). Plant sterols are naturally occurring plant compounds. The most important dietary sources are vegetable oils and vegetable-oil-based products such as margarines (Ling \& Jones, 1995). The most predominant plant sterols are sitosterol, campesterol and 
stigmasterol, and intake of these is estimated to be about $250 \mathrm{mg} / \mathrm{d}$ in non-vegetarians and about $500 \mathrm{mg} / \mathrm{d}$ for vegetarians (Ling \& Jones, 1995). Plant sterols reduce the absorption of cholesterol in the gut possibly by displacing cholesterol from the micelles, by limiting the intestinal solubility of cholesterol or by decreasing the hydrolysis of cholesterol esters in the small intestine (Ling \& Jones, 1995). Daily consumption of about $3 \mathrm{~g}$ of a mixture of vegetable-oil sterol esters, in particular esters of sitosterol, campesterol and stigmasterol, in a commonly used food, margarine, was recently reported to be effective in lowering plasma total- and LDL-cholesterol levels in normocholesterolaemic and mildly hypercholesterolaemic subjects (Weststrate \& Meijer, 1998). There have been very few studies published on the effect of doses of plant sterols less than $1 \mathrm{~g} / \mathrm{d}$ on plasma cholesterol levels in normocholesterolaemic subjects using commonly consumed foods (Pelletier et al. 1995).

The objective of the present study was to compare the effects of the consumption of two types of spreads (margarines) enriched with plant sterols, either sheanut-oil sterol (133 g sterol equivalents $/ \mathrm{kg}$ ), mainly 4,4-dimethylsterols, or non-esterified soyabean-oil sterols (31 g sterol equivalents/ $\mathrm{kg}$ ), mainly 4-desmethylsterols, in healthy volunteers on plasma total- and LDL-cholesterol levels. Flora, a spread not enriched with plant sterols but containing similar amounts and types of fatty acids, was used as the control. Our previous study (Weststrate \& Meijer, 1998) had shown a substantial plasma total- and LDL-cholesterol-lowering action of a spread enriched with esterified vegetable-oil sterols, mainly derived from soyabean oil $(110 \mathrm{~g}$ sterol equivalents $/ \mathrm{kg}$ ). Non-esterified soyabean-oil sterols might be somewhat more effective in lowering plasma totaland LDL-cholesterol levels compared with esterified soyabean-oil sterols, as sterols need to be in an unesterified or free state to inhibit cholesterol absorption (Peterson et al. 1953; Swell et al. 1956; Best \& Duncan, 1958). However, solubility of free plant sterols in spread is limited to approximately $30 \mathrm{~g} / \mathrm{kg}$. In our previous study a sheanutoil-sterol-enriched spread (101.5 g sterol equivalents $/ \mathrm{kg}$ ) was not effective in lowering blood cholesterol levels (Weststrate \& Meijer, 1998). A different fatty acid composition of this spread compared with the control product (less linoleic fatty acid and more oleic fatty acid) could have contributed to this result. In the present study, in contrast to our previous study, the fatty acid composition of the sheanut-oil-sterol-enriched spread was similar to the control spread. Blood chemistry and haematology were performed to assess possible adverse effects of spread consumption. Plasma $\alpha$ - plus $\beta$-carotene and lycopene levels were assessed only for the spreads which gave a statistically significant reduction in plasma total- and LDL-cholesterol concentrations, as we found in our previous study (Weststrate \& Meijer, 1998) a reduction of between 15 and $19 \%$ in plasma lipid-standardized levels of these lipophilic dietary compounds after intake of spreads enriched with plant sterols.

\section{Subjects and methods}

Subjects

Volunteers were recruited by advertisement from inhabitants of Vlaardingen (The Netherlands) and its surroundings, and from employees of Unilever Research Vlaardingen, with the exception of employees of the Unilever Nutrition Centre. Subjects' characteristics are shown in Table 1 . They ranged in age from 18 to 62 years and their BMI at the start of the study were between 19.2 and $29.6 \mathrm{~kg} / \mathrm{m}^{2}$. Alcohol drinking was below 21 units/week for females and below 28 units/ week for males. Volunteers had less than $10 \mathrm{~h} /$ week of intense exercise. Their entry plasma total cholesterol levels were below $8 \mathrm{mmol} / \mathrm{l}$ and plasma activities of $\mathrm{L}-\gamma$ glutamyltransferase (EC 2.3.2.2), alanine aminotransferase (EC 2.6.1.2), aspartate aminotransferase (EC 2.6.1.1) and alkaline phosphatase $(E C$ 3.1.3.1) were all within the normal ranges. Leucocyte, erythrocyte and platelet count, haemoglobin level and packed cell volume were all within the normal ranges. The volunteers were not participating in any other biomedical trial and had not donated blood within 1 month before the start of the study. Female volunteers were non-lactating and not pregnant. The study set-up was approved by our local Medical-Ethical Committee and written informed consent was obtained from all subjects.

\section{Study design}

The study had a balanced, double-blind, crossover design with a run-in period of 1 week with the control spread so that the volunteers could become accustomed to the use of the spreads. Immediately thereafter the experimental period of 9 weeks started in which each spread was given in random

Table 1. Descriptive characteristics of the volunteers participating in the plant-sterol-enriched spread study

(Mean values and standard deviations)

\begin{tabular}{|c|c|c|c|c|c|c|}
\hline \multirow[b]{2}{*}{ Characteristic } & \multicolumn{2}{|c|}{$\begin{array}{l}\text { Total } \\
(n 76)\end{array}$} & \multicolumn{2}{|c|}{$\begin{array}{l}\text { Males } \\
(n \text { 39) }\end{array}$} & \multicolumn{2}{|c|}{$\begin{array}{c}\text { Females } \\
(n 37)\end{array}$} \\
\hline & Mean & SD & Mean & SD & Mean & SD \\
\hline Age (years) & 44 & 11 & 45 & 12 & 43 & 11 \\
\hline Body weight $(\mathrm{kg})$ & $75 \cdot 2$ & $10 \cdot 7$ & 81.7 & $9 \cdot 6$ & 68.4 & $7 \cdot 1$ \\
\hline Body height (m) & 1.75 & 0.09 & 1.82 & 0.07 & 1.69 & 0.05 \\
\hline BMI $\left(\mathrm{kg} / \mathrm{m}^{2}\right)$ & 24.4 & $2 \cdot 4$ & $24 \cdot 7$ & 2.2 & 24.0 & 2.5 \\
\hline Sporting activities (h/week) & 1 & 2 & 1 & 2 & 1 & 1 \\
\hline Alcoholic beverage consumption (units/week) & 5 & 6 & 6 & 6 & 3 & 5 \\
\hline
\end{tabular}


order for 3 weeks at an intake level of $25 \mathrm{~g} / \mathrm{d}$. Subjects were randomly allocated over the six different period $\times$ group sequences. Groups were stratified according to sex. After each experimental period of 3 weeks, a fasting venous blood sample was taken from an antecubital vein with the subject seated in a chair. Body weight was measured on a digital balance (Mettler Instruments AG, Greifensee, Switzerland), with the subjects wearing light indoor clothing, without shoes and after voiding.

\section{Experimental spreads}

The test articles were specially prepared spreads fortified with non-esterified plant sterols derived from either edible vegetable oil (mainly soyabean oil) distillates (Henkel Corporation, LaGrange, IL, USA), or a sheanut oil concentrate in which the plant sterols were esterified, mainly with cinnamate $(69 \%)$ and acetate $(25 \%)$ (Loders Croklaan, Wormerveer, The Netherlands). The distillate or concentrate was used in spread production together with other edible oils and fats in order to achieve an acceptable product. The final plant sterol concentration was $31 \mathrm{~g} / \mathrm{kg}$ for the soyabean-oil sterol product and $133 \mathrm{~g} / \mathrm{kg}$ for the sheanut-oil sterol product, when expressed as free sterol equivalents. Flora (VandenBergh Foods, Purfleet, Surrey, UK), a spread not fortified with plant sterols, was used as the control. Table 2 shows the composition characteristics of the spreads. Tubs containing the individual daily amounts of spread were labelled with a blind product code. The spreads were intended for personal use and meant to replace all or part of the volunteers' habitual spread or butter used for spreading, but not to be used for baking or frying. Compliance was assessed by asking the volunteers about spread consumption and by weighing left-overs from the tubs.

\section{Lifestyle and dietary intake}

The volunteers were instructed to maintain their normal lifestyle and dietary and activity patterns during the entire study. The dietary intake during each period, i.e. over $21 \mathrm{~d}$, was assessed at the end of each period using a validated food-frequency questionnaire (Grootenhuis et al. 1995), with special emphasis on intakes of total energy, macronutrients, fatty acids, cholesterol and fibre. This questionnaire was modified for this study to give more detailed information on the intake of specific brands of spreads and dietary fats in the habitual diet in order to better evaluate fat composition of the habitual diet during each period. The answers to the questionnaire were checked for completeness by dietitians. Throughout the study volunteers recorded illnesses, medicine use, and any important deviations from their lifestyle or dietary and activity patterns.

\section{Measurements}

Blood samples. Fasting venous blood samples were taken on the last day of each period. Plasma total- and HDLcholesterol levels were determined using test kits from Boehringer (Mannheim, Germany). Plasma LDL-cholesterol level was calculated by the Friedewald formula (Friedewald et al. 1972). Plasma total and free glycerol concentrations were analysed using a total glycerol test kit (Roche, Basel, Switzerland) and a free glycerol test kit (Sigma, St Louis, MO, USA). Plasma triacylglycerol level was calculated as plasma total glycerol level $(\mathrm{mmol} / \mathrm{l})$ minus plasma free glycerol level $(\mathrm{mmol} / \mathrm{l})$. In blood, activities of $\mathrm{L}-\gamma$-glutamyltransferase and alkaline phosphatase and levels of bilirubin, creatinine, albumin and glucose were determined using test kits from Boehringer. The activities of aspartate aminotransferase and alanine aminotransferase and plasma levels of urea were determined using test kits from Roche. All determinations were done on a Cobas Mira S automated analyser (Roche). Plasma $\alpha$ - plus $\beta$-carotene and lycopene levels were only assessed in the blood samples which were taken after consumption of the soyabean-oil-sterol spread, which caused a statistically significant reduction in plasma total- and LDL-cholesterol concentrations, and in the blood samples which were taken

Table 2. Analysed composition of the spreads (per kg product) used in the plantsterol-enriched spread study

\begin{tabular}{|c|c|c|c|}
\hline Spread... & Flora* $^{*}$ & Soyabean† & Sheanutł \\
\hline Total fat $(\mathrm{g}) \S$ & 710 & 710 & 720 \\
\hline Water $(g)$ & 290 & 260 & 110 \\
\hline \multicolumn{4}{|l|}{ Fatty acid composition (g): } \\
\hline Saturated fatty acids & 160 & 140 & 190 \\
\hline Monounsaturated fatty acids & 210 & 220 & 190 \\
\hline Polyunsaturated fatty acids & 340 & 350 & 340 \\
\hline Free sterols plus sterol esters $(\mathrm{g})$ & 3 & 33 & 167 \\
\hline Sterol equivalents $(\mathrm{g})$ & 3 & 31 & 133 \\
\hline \multicolumn{4}{|l|}{ Sterol composition (g): } \\
\hline 4-Desmethylsterols & $2 \cdot 7$ & $30 \cdot 5$ & $4 \cdot 6$ \\
\hline 4-Monomethylsterols & 0.3 & 0.4 & 1.2 \\
\hline 4,4-Dimethylsterols & 0.2 & 0.2 & 127 \\
\hline Total vitamin $\mathrm{E}(\mathrm{mg}) \|$ & 430 & 460 & 300 \\
\hline$\alpha+\beta$-Carotene (mg) & 4.6 & 4.9 & 4.7 \\
\hline
\end{tabular}

${ }^{*}$ Control spread, not enriched with plant sterols.

† Spread enriched with $31 \mathrm{~g}$ soyabean-oil sterols $/ \mathrm{kg}$.

$\ddagger$ Spread enriched with $133 \mathrm{~g}$ sheanut-oil sterols $/ \mathrm{kg}$.

$\S$ Total trans fatty acid content of spreads was less than $10 \mathrm{~g} / \mathrm{kg}$ fat, sterols excluded.

\|I Includes $\alpha-, \beta$-, and $\gamma$-tocopherol. 
after consumption of Flora. This was done to assess the potential impact of the sterol-containing spread on the absorption of lipophilic dietary compounds. The plasma carotenoids were separated by HPLC on a Nucleosil $5-\mathrm{N}\left(\mathrm{CH}_{3}\right)_{2}$ column (Marchery \& Nagel, Düren, Germany) using $n$-heptane as eluent as described previously (Weststrate \& van het Hof, 1995). Plasma carotenoids were determined from the absorption at $450 \mathrm{~nm}$. Plasma carotenoid concentrations were standardized for plasma lipid (total cholesterol and triacylglycerol) levels as previously described (Weststrate \& van het Hof, 1995), because the sterol-enriched spreads did affect blood lipoprotein (plasma carotenoid carriers) concentrations. Haemoglobin concentrations, leucocyte count, platelet count and calculation of the packed cell volume were all performed on a Sysmex F-800 blood cell counter (Toa Medical Electronics Co. Ltd, Kobe, Japan). Staff conducting the laboratory analyses were blind to the group assignments.

Spreads. Directly after production and in each experimental period the spreads were analysed. Mean values for the composition are given in Table 2. During the study the stability of the spreads was checked once. The homogeneity of the sterols in the spreads was good, CV were generally less than $10 \%$ (results not shown). For fat analysis the sample was mixed with celite, freeze-dried and extracted with dichloromethane. After evaporation, the residue (fat) was weighed. The triacylglycerol content was calculated by subtracting the total sterol and/or sterol ester content from the total fat content. Fatty acid composition was analysed by methanolysis of the fatty acids. The methyl esters were extracted with heptane and analysed by GC (Hewlett Packard, Amstelveen, The Netherlands) using a CP-Sil 88 column (Chrompack, Middelburg, The Netherlands). Analysis of sterol types was performed according to previously described methods (Grob et al. 1989; Artho et al. 1993; Plank \& Lorbeer, 1993; Gordon \& Miller, 1997). The spreads were saponified with $\mathrm{KOH}$ before extracting the unsaponifiable part into cyclohexane. Thin-film chromatography (with as TLC-eluent a mix of toluene with ethyl acetate) was used for separating the 4-desmethylsterol, the 4-monomethylsterol and the 4,4-dimethylsterol fractions $(10 \mathrm{~g}$ ultraphor/l water as detection reagent) with $\beta$ cholestanol as internal standard. The fractions were extracted with a mixture of chloroform, diethyl ether and ethanol. After silylizing with pyridine and $\mathrm{N}, \mathrm{O}$-bis(trimethylsilyl)trifluoroacetamide this fraction was analysed by GC (Fisions Instruments, Milan, Italy) using a CP-Sil 19 column (Chrompack). Detection was by flame ionization detector (Fisions Instruments). For determination of the amounts of free and esterified sterols a portion of the isolated fat phase was silylated in order to convert the free sterols into trimethylsilyl ether derivatives. After isolation of the free sterols and steryl fatty acid esters from the triacylglycerol matrix by means of normal-phase HPLC, the free sterols and steryl fatty acids were quantified by GC using internal standards. Sterol equivalents were calculated by multiplying the weight percentages of steryl fatty acid esters by a factor 0.608 (calculated from the average molecular mass of sterols and fatty acids in soyabean oil). The total sterol equivalents were obtained by adding the concentration of free sterols and the sterol equivalents from the steryl fatty acid esters. Vitamin E was analysed by a straight-phase HPLC method, based on international standard operation procedures (American Oil Chemists' Society, 1992). Carotenoid content was assessed for Flora and the spread containing free soyabean-oil sterols. For the carotenoid analysis the sample was mixed with diethyl ether. After vortex-mixing the extract was dried under $\mathrm{N}_{2}$ and dissolved in $n$-heptane containing the internal standard, ethyl- $\beta$-apo8 -carotenoate. The analysis was performed by straightphase HPLC using an ET 200/8/4 nucleosil 5-N( $\left(\mathrm{CH}_{3}\right)_{2}$ column (Marchery \& Nagel) and $n$-heptane-isopropanol $(1000: 24, \mathrm{v} / \mathrm{v})$ as mobile phase at a flow rate of $1 \mathrm{ml} / \mathrm{min}$ and a column temperature of $20^{\circ}$. Carotenoids were detected by u.v.-visible detection at $450 \mathrm{~nm}$ for $\alpha$-plus $\beta$-carotene and at $470 \mathrm{~nm}$ for lycopene.

\section{Statistical analysis}

Differences in plasma variables and dietary intake between spread groups were initially evaluated using ANOVA using as factors subject, period, spread, carry-over, sex and sex $\times$ spread. The carry-over effect was subsequently removed from the model as it was not statistically significant. Blood lipid and carotenoid data were $\log$ normalized before analysis. Geometric means are given with $95 \% \mathrm{CI}$ and have been back transformed (Table 4). Differences between spread groups were assessed using the Tukey multiple comparison test (Miller, 1981). A $P$ value of 0.05 was considered statistically significant. The Statistical Analysis Systems program version 6.12 (1987; SAS Institute Inc., Cary, NC, USA) was used for analysis. All the statistical significance levels are given two-sided.

\section{Results}

Thirty-nine men and thirty-seven women completed the study. During the study two women dropped out because of medicine use and their data were not used in final analysis. Two people missed one period because of diarrhoea and one person did not give a blood sample in one period.

\section{Compliance}

The mean intakes of Flora, the vegetable-oil-sterol spread and the spread enriched with sheanut-oil sterols, estimated by weighing the left-over spread in the tubs after each period, were respectively $24.2 \mathrm{~g} / \mathrm{d}, 24.8 \mathrm{~g} / \mathrm{d}$ and $24.4 \mathrm{~g} / \mathrm{d}$ with CV $1.1 \%, 1.9 \%$ and $4.0 \%$ (results not shown). The mean daily total plant sterol intakes were respectively $0.08 \mathrm{~g}, 0.8 \mathrm{~g}$ and $3.2 \mathrm{~g}$. The habitual dietary intake (including the test spread consumption) is given in Table 3. Except for the statistically significant but very small difference in intake of saturated fatty acids (in \% energy) between the soyabean-oil-sterol spread and the sheanut-oil-sterol spread, no statistically significant differences were observed among the groups in dietary intake. The average body weight in the group with the spread containing free soyabean oil sterols was slightly higher than the average body weight in the Flora group (75.5 kg v. 75.2 kg). However, an analysis for males and females separately revealed no statistically 
Table 3. Energy and dietary nutrient intakes (as percentage of total energy unless otherwise indicated) of the volunteers participating in the plant-sterol-enriched spread study

(Mean values and $95 \%$ confidence intervals)

\begin{tabular}{|c|c|c|c|c|c|c|}
\hline \multirow{2}{*}{$\begin{array}{l}\text { Spread... } \\
\text { Nutrient }\end{array}$} & \multicolumn{2}{|c|}{ Flora† } & \multicolumn{2}{|c|}{ Soyabean $\ddagger$} & \multicolumn{2}{|c|}{ Sheanut§ } \\
\hline & Mean & $95 \% \mathrm{Cl}$ & Mean & $95 \% \mathrm{Cl}$ & Mean & $95 \% \mathrm{Cl}$ \\
\hline Energy $(\mathrm{kJ} / \mathrm{d})$ & 9977 & 9732,10221 & 10060 & 9816,10304 & 10019 & 9775,10264 \\
\hline Total fat & 38.3 & $37 \cdot 8,38 \cdot 8$ & 38.3 & $37 \cdot 8,38.8$ & 38.4 & $37.9,38.9$ \\
\hline Saturated fatty acids & 13.9 & $13 \cdot 7,14 \cdot 2$ & $13 \cdot 8$ & $13 \cdot 6,14 \cdot 1$ & $14 \cdot 3^{*}$ & $14 \cdot 0,14 \cdot 6$ \\
\hline Monounsaturated fatty acids & $12 \cdot 8$ & $12 \cdot 6,13 \cdot 0$ & $12 \cdot 9$ & $12 \cdot 6,13 \cdot 1$ & 12.5 & $12 \cdot 3,12 \cdot 7$ \\
\hline Polyunsaturated fatty acids & 9.2 & $9.1,9.4$ & 9.2 & $9 \cdot 1,9.4$ & $9 \cdot 2$ & $9 \cdot 1,9.4$ \\
\hline Protein & $15 \cdot 6$ & $15 \cdot 4,15 \cdot 9$ & $15 \cdot 4$ & $15 \cdot 2,15 \cdot 6$ & $15 \cdot 6$ & $15 \cdot 4,15 \cdot 9$ \\
\hline Carbohydrates & 43.2 & $42 \cdot 7,43 \cdot 8$ & 43.3 & $42 \cdot 7,43 \cdot 8$ & 43.1 & $42 \cdot 6,43 \cdot 7$ \\
\hline Cholesterol (mg/d) & 246 & 236,256 & 247 & 238,257 & 242 & 232,252 \\
\hline Fibre $(g / d)$ & $26 \cdot 0$ & $25 \cdot 3,26 \cdot 8$ & $26 \cdot 7$ & $26 \cdot 0,27 \cdot 5$ & $26 \cdot 3$ & $25 \cdot 5,27 \cdot 0$ \\
\hline
\end{tabular}

Mean value was significantly different from that for soyabean spread: * $P<0.05$.

† Control spread, not enriched with plant sterols.

‡ Enriched with $31 \mathrm{~g}$ soyabean-oil sterols $/ \mathrm{kg}$.

$\S$ Enriched with $133 \mathrm{~g}$ sheanut-oil sterols $/ \mathrm{kg}$.

significant differences in average body weight between the groups. No important deviations from lifestyle, dietary or activity pattern occurred during the study.

\section{Blood variables}

Table 4 shows the plasma lipid, $\alpha$-plus $\beta$-carotene, and lycopene concentrations based on the 3-week sampling result. There was no interaction effect between spread group and sex. The soyabean-oil-sterol spread lowered plasma total- and LDL-cholesterol levels significantly compared with Flora without an effect on plasma HDL-cholesterol levels. Consequently the ratio LDL: HDL-cholesterol was also statistically significantly reduced. The sheanut-oilsterol spread did not statistically significantly change blood lipid levels compared with Flora. Fig. 1 shows the individual changes in plasma LDL-cholesterol concentrations after consumption of the soyabean-oil-sterol spread and the sheanut-oil-sterol spread compared with the control spread (Flora). In most subjects the soyabean-oil-sterol spread caused a decrease in plasma LDL-cholesterol concentrations, however, some subjects showed a small increase. Two subjects showed large increases in plasma total- and LDL-cholesterol levels after consumption of the soyabean-oil-sterol spread, probably due to chance. The sheanut-oil-sterol spread caused an increase in plasma LDL-cholesterol concentrations in more subjects. Plasma triacylglycerol levels were not affected by the spreads. The soyabean-oil-sterol spread caused a statistically significant reduction in plasma lycopene concentration but not in plasma $\alpha$ - plus $\beta$-carotene level. Standardization of the plasma lycopene concentration for decreased lipid did diminish the lowering effect of soyabean-oil-sterol spread on blood lycopene level, but the effect still remained statistically significant. All values of the blood variables during the study were within the normal ranges.

\section{Discussion}

This double-blind crossover study in healthy adults showed that daily consumption of $25 \mathrm{~g}$ of a spread enriched with free soyabean-oil sterols (31 g sterol equivalents $/ \mathrm{kg} ; 0.8 \mathrm{~g} / \mathrm{d}$ ),

Table 4. Plasma lipid, $\alpha$ - plus $\beta$-carotene and lycopene concentrations in volunteers consuming a control spread (Flora) or plant-sterol-enriched spreads $(25 \mathrm{~g} / \mathrm{d})$ for 3 weeks $\dagger$

(Mean values and $95 \%$ confidence intervals for seventy-five subjects)

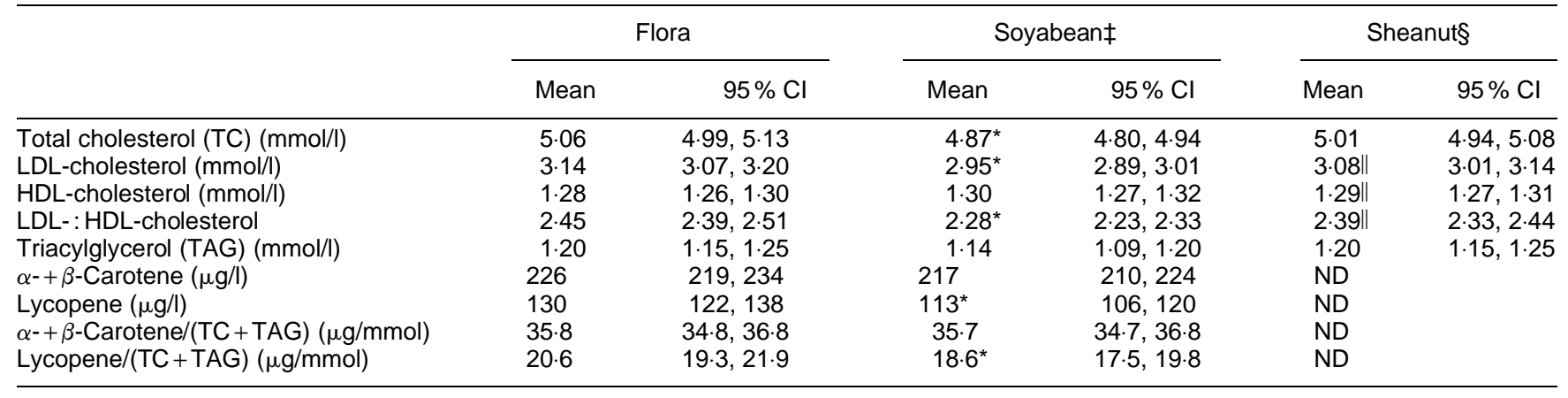

ND, not determined.

Mean values were significantly different from those for Flora: ${ }^{*} P<0.05$.

†For details of diets and procedures, see Table 2 and pp. 274-276.

¥ Spread enriched with $31 \mathrm{~g}$ soyabean-oil sterols $/ \mathrm{kg}$.

§ Spread enriched with $133 \mathrm{~g}$ sheanut-oil sterols $/ \mathrm{kg}$.

II $n 74$. 


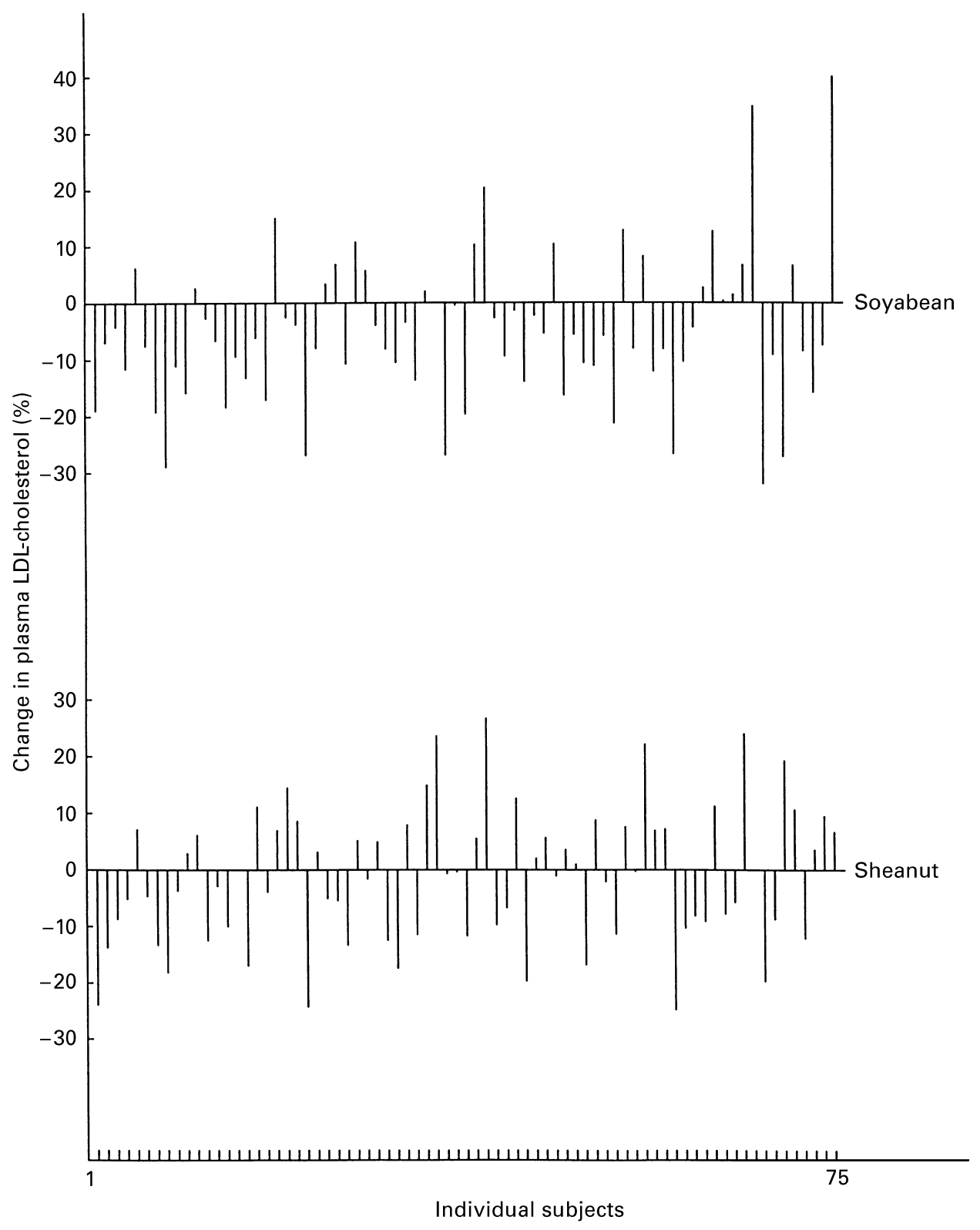

Fig. 1. Changes (\%) in the plasma LDL-cholesterol levels of individual subjects after consumption of spreads enriched with soyabean-oil sterols or sheanut-oil sterols $(25 \mathrm{~g} / \mathrm{d}$ for 3 weeks) compared with a control spread (Flora). For details of spreads and procedures, see Table 2 and pp. 274-276.

lowered plasma total- and LDL-cholesterol concentrations respectively by $3.8 \%$ and $6 \%$ (both $0.19 \mathrm{mmol} / \mathrm{l}$ ) compared with a spread with similar fatty acid content not enriched with these sterols. No effect on plasma HDL-cholesterol or triacylglycerol concentrations was found. A similar study with somewhat younger subjects showed reductions in plasma total- and LDL-cholesterol concentrations of respectively $4.9 \%(0.26 \mathrm{mmol} / \mathrm{l})$ and $6.7 \%(0.20 \mathrm{mmol} / \mathrm{l})$ after consumption of a spread enriched with esterified soyabean sterols at a similar intake level of $0.8 \mathrm{~g} / \mathrm{d}$ (Hendriks et al. 1999). This indicates that, as sterols need to be in a free state to inhibit cholesterol absorption (Peterson et al. 1953; Swell et al. 1956; Best \& Duncan, 1958), intestinal hydrolysis of plant sterol esters by cholesterol esterase is not a rate limiting factor, at this level of plant sterol intake, in determining the efficacy of plant sterols to lower blood cholesterol levels. Esterification of sterols is necessary to increase the solubility of sterols in fat (Jandacek et al. 1977). In our previous study (Weststrate \& Meijer, 1998) a four-fold higher intake of esterified soyabean-oil sterols $(3.3 \mathrm{~g} / \mathrm{d})$ caused a two-fold higher reduction in plasma total- and LDL-cholesterol concentrations compared with this study, respectively $8.3 \%(0.43 \mathrm{mmol} / \mathrm{l})$ and $13 \%$ $(0.44 \mathrm{mmol} / \mathrm{l})$. This indicates that there is a non-linear relationship between plant sterol intake and blood cholesterol level reduction, which has also been found by other investigators (Lees et al. 1977).

As in our previous study (Weststrate \& Meijer, 1998) the 
4-Desmethylsterols
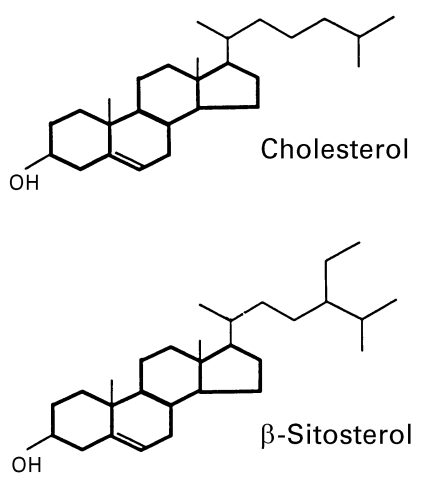
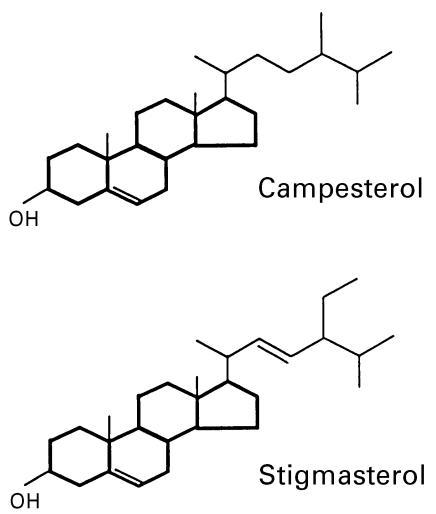

4,4-Dimethylsterols
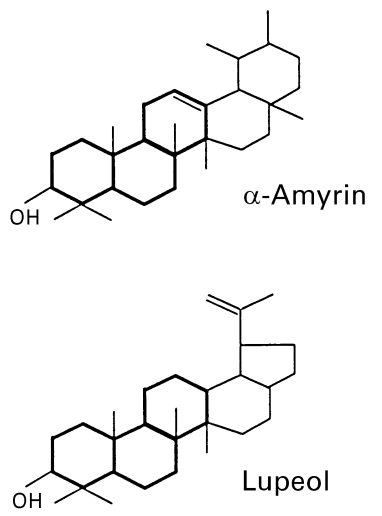

Fig. 2. Structure of 4-desmethylsterols and 4,4-dimethylsterols.

sheanut-oil-sterol spread was not effective in lowering blood cholesterol. In the current study, differences in fatty acid composition between control and sheanut-oil-sterol spreads did not confound the outcome as they may have done in our previous study (Weststrate \& Meijer, 1998). The sheanut-oil sterols are primarily phenolic acid esters of 4,4-dimethylsterols, whereas the soyabean-oil product contained 4-desmethylsterols. The structure of 4-desmethylsterols is more similar to cholesterol than the structure of 4,4-dimethylsterols (Fig. 2). This may offer more opportunity for competition with cholesterol for incorporation in mixed micelles, the most likely mechanism for the bloodcholesterol-lowering action of sterols (Ling \& Jones, 1995). This study indicates that sheanut-oil sterols will not be efficacious in lowering plasma cholesterol levels. The present study was not a strictly controlled feeding trial and changes in consumers behaviour may have affected the outcome. However, the study was double-blinded and compliance with the instructions to consume the spreads appeared to be excellent. Moreover nutrient and energy intakes, including those of fatty acids, cholesterol and fibre as well as body weights were very similar for the different spread groups. We believe, therefore, that the results of this trial are valid. Spread consumption was very close to the recommended use level of $25 \mathrm{~g} / \mathrm{d}$. Only two people $(2.6 \%)$ dropped out, both for reasons not related to consumption of the spread. The number of volunteers consuming a given spread was similar for all products (seventy-five). The habitual dietary intake of fatty acids, fibre and cholesterol, which may affect blood lipid levels, was not statistically significantly different between the spread groups, except for a small and irrelevant difference in energy percentage of saturated fatty acids between the soyabean-oil-sterol spread and the sheanut-oil-sterol spread ( $<1 \%$ energy).

In two earlier studies esterified plant sterols at an intake level of approximately $3 \mathrm{~g} / \mathrm{d}$ reduced plasma lipid standardized concentrations of $\alpha$ - plus $\beta$-carotene approximately $15-20 \%$ and of lycopene approximately $10-15 \%$ (Weststrate \& Meijer, 1998; Hendriks et al. 1999), whereas no reduction was observed for plasma-lipid-standardized vitamin E. Gylling et al. (1996) also showed an effect at a similar intake level of sitostanol ester on plasma $\alpha$ - and $\beta$ carotene levels. The three-fold lower level of non-esterified plant sterols used in the present study did not lead to reduction of plasma lipid-standardized concentrations of $\alpha$ - plus $\beta$-carotene. However, the lipid standardized plasma lycopene levels were statistically significantly reduced by $9.5 \%$. This reduction was not statistically significant at a similar intake level of esterified plant sterols (Hendriks et al. 1999). However, in the latter study a small significant effect on plasma $\alpha$ - and $\beta$-carotene was found. Thus, lipid-standardized plasma carotenoid levels are not or slightly affected by esterified or non-esterified plant sterols intakes of up to $1 \mathrm{~g} / \mathrm{d}$.

The clinical importance of a lowering of plasma levels of carotenoids is difficult to ascertain. Carotenoids may have positive effects on health as indicated primarily by epidemiological studies (Mayne, 1996). The role of carotenoids, other than their provitamin A activity, is however, not established with reasonable certainty. It is currently not possible to determine a minimum plasma carotenoid level, for carotenoids as a group or for individual carotenoids, below which it is conclusively established that health risks or benefits would change, neither is it possible to set limits for reductions in plasma carotenoid levels, either for carotenoids as a group or for individual carotenoids. It seems, however, prudent to aim, if at all possible, for small or negligible long-term reductions of blood carotenoid levels in consumers of sterol-enriched products. Giovannucci et al. (1995) showed that the relative risk for prostate cancer was about $20 \%$ lower in men consuming relatively high amounts of lycopene compared with those with lower intakes. The mean difference in intake between the high and low quintile was about $9 \mathrm{mg} / \mathrm{d}$. There is no information on the dose-response relationship between increased dietary lycopene intakes and changes in plasma lycopene levels. A study by Yeum et al. (1996) indicates that a controlled diet containing $3.3 \mathrm{mg}$ lycopene/d increased plasma lycopene levels in US men and women compared with baseline by about $60 \%$. No baseline lycopene intake data were, however, given. Baseline lycopene intake in US men and women may be estimated to be about $2 \mathrm{mg} / \mathrm{d}$ (Nebeling et al. 
1997). This suggests that a difference of more than $1 \mathrm{mg} / \mathrm{d}$ lycopene intake will correspond to a difference of plasma lycopene levels of about $60 \%$. In the present study we observed a reduction of $13 \%$ in unstandardized plasma lycopene levels. We hypothesize that this difference in plasma lycopene levels may be expected to correspond to a difference in dietary lycopene intake of about $0.2 \mathrm{mg} / \mathrm{d}$. The study of Giovanucci et al. (1995) showed that a difference in intake of about $9 \mathrm{mg} / \mathrm{lycopene} / \mathrm{d}$ was associated with a change in relative risk for prostate cancer of about $20 \%$, or about a $2 \%$ change in relative risk per $1 \mathrm{mg} / \mathrm{d}$ change in dietary lycopene intake. Even when we assume that the results of this study indicate a causal relationship between reduced lycopene intake and increased risk of prostate cancer (which is not proven) the decrease in plasma lycopene levels observed in our present study translates to a negligible change in relative risk for prostate cancer.

Because of the within-person variations in plasma totaland LDL-cholesterol levels, which are up to about $10 \%$ (analytical variation excluded) (Smith et al. 1993), not all individuals showed a reduction in plasma total- and LDLcholesterol concentrations after consumption of the spread enriched with free soyabean-oil sterols (which caused average reductions in plasma total- and LDL-cholesterol levels of respectively $3.8 \%$ and $6 \%$, smaller than the withinperson variations for plasma total- and LDL-cholesterol levels). These increases in plasma total- and LDL-cholesterol concentrations are thus related to chance. If more measurements had been done per individual to establish his or her 'true' blood lipid levels, the chance of observing increases would be minimal and more accurate individual values of plasma total- and LDL-cholesterol concentrations would have been obtained. Plant sterols have been part of the human diet for a very long time and for vegetarians, for example, plant sterol intake can be substantial, e.g. $500 \mathrm{mg} / \mathrm{d}$ (Ling \& Jones, 1995), which is in contrast to the intake of plant stanols. The introduction of plant-sterol-enriched products would in itself not introduce new compounds into the diet: it might, however, cause an increase in the exposure to plant sterols in consumers of such products. The possible health risks associated with such an introduction need to be carefully assessed. Current evidence indicates that plant sterols are unlikely to raise severe concerns regarding possible human health risks. Many human studies with dose levels up to $25 \mathrm{~g} /$ plant sterols/d for up to several months have been performed without adverse effects (reviewed by Pollak \& Kritschevsky, 1981). The only undesirable effect observed have been occasional gastrointestinal disturbances, e.g. constipation (Lees et al. 1977; Kane \& Malloy, 1982) and diarrhoea, which are more related to the vehicle (large volumes of vegetable oils) used to administer the plant sterols. The only reported adverse effects of plant sterols have been in individuals with phytosterolaemia. Phytosterolaemia is a vary rare inherited lipid storage disease, affecting a few individuals per million, in which a high proportion of plant sterols is absorbed from the intestine (Salen et al. 1992). The condition has a high risk of premature atherosclerosis. Individuals with this condition should avoid the consumption of plant sterols. However, for the general population this increased absorption of plant sterols does not occur, rather the plant sterols are poorly absorbed and, if absorbed, rapidly cleared (Ling \& Jones, 1995). This is well illustrated by the results of a previous study from our group where an intake of about $3.3 \mathrm{~g} / \mathrm{d}$ of esterified vegetable oil plant sterols from a spread $v$. an intake of about $100 \mathrm{mg} / \mathrm{d}$ of plant sterols from a control spread raised plasma levels of sitosterol from $3.3 \mathrm{mg} / \mathrm{l}$ to $4.6 \mathrm{mg} / \mathrm{l}$ and of campesterol from $7 \mathrm{mg} / \mathrm{l}$ to $12.1 \mathrm{mg} / \mathrm{l}$ (Weststrate \& Meijer, 1998). Thus, in spite of significant increases in plant sterol intake i.e. of more than a factor of 30 , the increase in plant sterol plasma levels was less than a factor of 2 . We have, in addition to the present study, performed a number of studies with high dose levels of plant sterols addressing specific toxicological and physiological issues. These studies have not shown evidence of oestrogenic, toxic or adverse effects of plant sterols on bile acid and neutral sterol excretion or the gut microflora (Ayesh et al. 1999; Baker et al. 1999; Hepburn et al. 1999; Weststrate et al. 1999).

We estimate, based on a meta-analysis by Law et al. (1994) that the observed reductions in total and LDLcholesterol concentrations for the soyabean-oil sterol spread could help in reducing CHD risk by about $15 \%$ at age 40 and $6 \%$ at age 70 . According to a study of Stampfer et al. (1991) the predicted reduction in risk for CHD would be about $10 \%$.

We conclude that this study shows that consumption of a spread enriched with a low concentration of soyabean-oil sterols in unesterified form is effective in reducing mean total- and HDL-cholesterol levels in free-living subjects by about 4 and $6 \%$ respectively. These decreases are similar to what may be expected from free-living subjects adhering to prudent diets (Tang et al. 1998). We have also shown that these decreases occur with limited effects on plasma levels of carotenoids. It would be of public health importance if part of the fat or water in edible fat-containing products could be replaced by plant sterols. This would be predicted to help in reducing the risk of cardiovascular disease in the population.

\section{Acknowledgements}

The authors want to express their gratitude to the team that conducted this study, M. P. van Amerongen, C. G. Blonk, C. Bauer-Plank, A. H. L. M. Cambeen, J. A. Don, G. P. Dubbelman, W. M. C. Dubelaar, H. A. Engels, J. J. F. van de Graaf, E. Haddeman, M. van der Ham, S. Y. Gielen, R. G. J. M. Jacobs, L. C. Lievense, A. J. M. Maniera, J. N. N. J. Mathot, W. G. L. van Nielen, W. G. van Oort, J. van Toor, A. S. Kastelein, M. Welling, A. Wiersma and J. E. C. van Wijk. We also thank the volunteers for their enthusiastic participation.

\section{References}

American Oil Chemists' Society (1992) Determination of tocopherols and tocotrienols in vegetable oils and fats by HPLC. In Official Methods and Recommended Practices of the American Oil Chemists' Society, 5th ed., [D Firestone, editor]. Champaign, IL: AOCS.

Artho A, Grob K \& Mariani C (1993) On-line LC-GC for the 
analysis of minor components in edible oils and fats - The direct method involving silylation. Fat Science Technology 95, 176180.

Ayesh R, Weststrate JA, Drewitt PA \& Hepburn PA (1999) Faecal short chain fatty acid and microflora content, faecal bacterial enzyme activity and plasma female sex hormones in healthy normolipidemic volunteers consuming a controlled diet either with or without a phytosterol-ester enriched margarine. Food and Chemical Toxicology (In the Press).

Baker VA, Hepburn PA, Kennedy SJ, Jones PA, Lea LJ, Sumpter JP \& Ashby J (1999) Safety evaluation of phytosterol esters. Part 1. Assessment of oestrogenicity using a combination of in vivo and in vitro assays. Food and Chemical Toxicology 37, 13-22.

Best MM \& Duncan CH (1958) Effects of the esterification of supplemental cholesterol and sitosterol in the diet. Journal of Nutrition 65, 169-181.

Cucherat M \& Boissel JP (1993) Meta-analysis of results from clinical-trials on prevention of coronary heart-disease by lipidlowering interventions. Clinical Trials and Meta-analysis 28, 109-129.

Farquhar JW \& Sokolow M (1958) Response of serum lipids and lipoproteins of man to beta-sitosterol and safflower oil - A long term study. Circulation 17, 890-899.

Friedewald WT, Levy RI \& Frederickson DS (1972) Estimation of the concentration of low-density lipoprotein cholesterol in plasma, without the use of the preparative ultracentrifuge. Clinical Chemistry 18, 499-502.

Giovannucci E, Ascherio A, Rimm EB, Stampfer MJ, Colditz GA \& Willett WC (1995) Intake of carotenoids and retinol in relation to risk of prostate cancer. Journal of the National Cancer Institute 87, 1767-1776.

Gordon MH \& Miller LAD (1997) Development of steryl ester analysis for the detection of admixtures of vegetable oils. Journal of the American Oil Chemists' Society 74, 505-510.

Grob K, Lanfranchi M \& Mariani C (1989) Determination of free and esterified sterols and of wax esters in oils and fats by coupled liquid chromatography-gas chromotography. Journal of Chromatography 471, 397-405.

Grootenhuis PA, Westenbrink S, Sie CMTL, Neeling JND, Kok FJ \& Bouter LM (1995) A semiquantitative food frequency questionnaire for use in epidemiologic research among elderly: validation by comparison with dietary history. Journal of Clinical Epidemiology 48, 859-868.

Gylling HK, Puska P, Vartiainen E \& Miettinen TA (1996) Serum retinol, $\alpha$-tocopherol, carotenes and lipid peroxide production during serum cholesterol lowering by sitostanol ester margarine in a mildly hypercholesterolemic population. Circulation 94, Suppl. I-578, Abstr 3379.

Hendriks HFL, Weststrate JA, van Vliet T \& Meijer GW (1999) Spreads enriched with three different levels of vegetable oil sterols and the degree of cholesterol lowering in normocholesterolaemic and mildly hypercholesterolaemic subjects. European Journal of Clinical Nutrition 53, 319-327.

Hepburn PA, Horner SA \& Smith M (1999) Safety evaluation of phytosterol esters. Part 2. Subchronic 90-day oral toxicity study on phytosterol-esters - a novel functional food. Food and Chemical Toxicology (In the Press).

Jandacek RJ, Webb MR \& Mattson FH (1977) Effect of an aqueous phase on the solubility of cholesterol in an oil phase. Journal of Lipid Research 18, 203-210.

Kane JP \& Malloy MJ (1982) Treatment of hypercholesterolemia. Medical Clinics of North America 66, 537-550.

Law MR, Wald MJ \& Thompson SG (1994) By how much and how quickly does a reduction in serum cholesterol concentrations lower risk of ischaemic heart disease? British Medical Journal 308, 367-372.

Lees AM, Mok HYI, Lees RS, McCluskey MA \& Grundy SM
(1977) Phytosterols as cholesterol-lowering agents: clinical trials in patients with hypercholesterolemia and studies of sterol balance. Atherosclerosis 28, 325-338.

Levine GN, Keany JF \& Vita JA (1995) Cholesterol reduction in cardiovascular disease. New England Journal of Medicine 332, 512-521.

Ling WH \& Jones PJH (1995) Minireview dietary phytosterols: a review of metabolism, benefits and side effects. Life Sciences 57, 195-206.

Mayne ST (1996) Beta-carotene, carotenoids, and disease prevention in humans. FASEB Journal 10, 690-701.

Mensink RP \& Katan MB (1992) Effect of dietary fatty-acids on serum-lipids and lipoproteins - a meta-analysis of 27 trials. Arteriosclerosis and Thrombosis 12, 911-919.

Miller RG (1981) Simultaneous Statistical Interference. New York, NY: Springer Verlag.

Nebeling LC, Forman MR, Graubard BI \& Snyder RA (1997) Changes in the carotenoid intake in the United States: The 1987 and 1992 National Health Interview Surveys. Journal of the American Dietetic Association 97, 991-996.

Oster P, Schlierf G, Heuck CC, Greten H, Gundert-Remy U, Haase W, Klose G, Nothelfer A, Raetzer H, Schellenberg B \& Schmidt-Gayk H (1976) Sitosterol in familial hyperlipoproteinemia type-2. Deutsche Medizinische Wochenschrift 101, $1308-1311$

Peterson DW, Shneour EA, Peek NF \& Gaffey HW (1953) Dietary constituents affecting plasma and liver cholesterol in cholesterol-fed chicks. Journal of Nutrition 50, 191-201.

Pelletier X, Belbraouet S, Mirabel D, Mordret F, Perrin JL, Pages X \& Debry G (1995) A diet moderately enriched in phytosterols lowers plasma cholesterol concentrations in normocholesterolemic humans. Annals of Nutrition and Metabolism 39, 291-295.

Plank C \& Lorbeer E (1993) Analysis of free and esterified sterol in vegetable oil methyl esters by capillary gas chromatography. Journal of High Resolution Chromatography 16, 483-487.

Pollak OJ \& Kritchevsky D (1981) Sitosterol. Monographs on Atherosclerosis. Basel: S. Karger.

Probstfield JL \& Rifkind BM (1991) The lipid-research-clinics coronary primary prevention trial - design, results, and implications. European Journal of Clinical Pharmacology 40, S69-S75.

Reitsma JB (1995) Hart- en vaatziekten in Nederland 1995: cijfers over ziekte en sterfte (Cardiovascular Diseases in The Netherlands 1995: Morbidity and Mortality Numbers). The Hague: Nederlandse Hartstichting.

Ripsin CM, Keenan JM, Jacobs DR, Elmer PJ, Welch RR, Van Horn L, Kiang Liu, Turnbull WH, Thye FW, Kestin M, Hegsted M, Davidson DM, Davidson MH, Dugan LD, DemarkWahnefried W \& Beling S (1992) Oat products and lipid lowering. Journal of the American Medical Association 267, 3317-3325.

Salen G, Shefer S, Lien NY, Ness GC, Tint GS \& Shore V (1992) Sitosterolemia. Journal of Lipid Research 33, 945-955.

Schwartzkopff W \& Jantke HJ (1978) Dose-effect of beta-sitosterin in type-IIA and type-IIB hypercholesterolemias. Munchener Medizinische Wochenschrift 120, 1575-1578.

Smith SJ, Cooper GR, Myers GL \& Sampson EJ (1993) Biological variability in concentrations of serum lipids: sources of variation among results from published studies and composite predicted values. Clinical Chemistry 39, 1012-1022.

Stampfer MJ, Sacks FM, Salvani S, Willett WC \& Hennekens CH (1991) A prospective study of cholesterol, apolipoproteins, and the risk of myocardial infarction. New England Journal of Medicine 325, 373-381.

Steinberg D \& Witztum L (1990) Lipoproteins and atherogenesis. Current concepts. Journal of the American Medical Association 264, 3047-3052. 
Swell L, Boiter TA, Field H \& Treadwell CR (1956) The absorption of plant sterols and their effect on serum and liver sterol levels. Journal of Nutrition 58, 385-395.

Tang JL, Armitage JM, Lancaster T, Silagy CA, Fowler GH \& Neil HAW (1998) Systematic review of dietary intervention trials to lower blood total cholesterol in free-living subjects. British Medical Journal 316, 1213-1220.

Weststrate JA, Ayesh R, Bauer-Plank C \& Drewitt PN (1999) Safety evaluation of phytosterol-esters part 4: faecal concentrations of bile acids and neutral sterols in healthy normolipidemic volunteers consuming a controlled diet either with or without a phytosterol-ester enriched margarine. Food and Chemical Toxicology (In the Press).
Weststrate JA \& Meijer GW (1998) Plant sterol-enriched margarines and reduction of plasma total- and LDL-cholesterol concentrations in normocholesterolaemic and mildly hypercholesterolaemic subjects. European Journal of Clinical Nutrition 52, 334-343.

Weststrate JA \& van het Hof KH (1995) Sucrose polyester and plasma carotenoid concentrations in healthy subjects. American Journal of Clinical Nutrition 62, 591-597.

Yeum KJ, Booth SL, Sadowski JA, Liu C, Tang G, Krinsky NI \& Russell RM (1996) Human plasma carotenoid response to the ingestion of controlled diets high in fruits and vegetables. American Journal of Clinical Nutrition 64, 594-602. 